\title{
PENGARUH SENAM KEGEL TERHADAP PENYEMBUHAN LUKA PADA IBU POST PARTUM
}

\author{
Eka Yulia Fitri* $\diamond$, Aprina**, Setiawati* \\ *Prodi Keperawatan Universitas Malahayati \\ **Jurusan Keperawatan Poltekkes Kemenkes Tanjungkarang \\ $\diamond$ Corresponding Outhor:
}

\begin{abstract}
Risiko tinggi/komplikasi adalah keadaan penyimpangan dari normal, yang secara langsung menyebabkan kesakitan dan kematian ibu maupun bayi. Tujuan Penelitian : diketahui pengaruh senam kegel terhadap penyembuhan luka pada ibu post partum. Jenis penelitian kuantitatif, desain penelitian metode quasi eksperimen dengan pendekatan Post test with control group design, objek penelitian adalah pengaruh senam kegel dengan ruptur perineum. Populasi dalam penelitian ini adalah seluruh ibu bersalin. Populasi penelitian ini adalah seluruh ibu bersalin primi dengan jumlah sampel adalah 60 responden. Analisis data menggunakan uji t independen. Hasil Penelitian : Rata-rata penyembuhan luka pada kelompok eksperimen sebelum senam kegel adalah 10,73 dan setelah senam kegel 4.40. Rata-rata penyembuhan luka pada kelompok kontrol pada pengukuran pertama adalah 10.53 dan pengukuran kedua 5.20. Ada penyembuhan luka pada ibu post partum ( $p$-value 0,015) dengan nilai beda mean 0,800 dan t-test 2,592. Kepada perawat diharapkan selalu mengajarkan senam kegel pada ibu hamil dan terutama pada ibu-ibu primigravida.
\end{abstract}

Kata kunci: senam kegel, penyembuhan luka, ibu post partum

\section{LATAR BELAKANG}

Robekan yang terjadi pada perineum sewaktu proses persalinan atau disebut juga laserasi perineum yang terjadi saat persalinan dengan tindakan seperti ekstraksi forsep, ekstraksi vakum, versi ekstraksi, kristeller (dorongan pada fundus uteri) dan episiotomi dapat menyebabkan robekan jalan lahir. Laserasi perineum dapat diklasifikasikan berdasarkan derajat laserasi yaitu derajat I, derajat II, derajat III dan derajat IV. Perdarahan postpartum sering terjadi pada laserasi perineum derajat I dan II (Winkjosastro, 2007).

National Hospital Discharge Survey (2012) melaporkan bahwa di Amerika Serikat angka morbiditas ibu hamil dan bersalin diantaranya adalah komplikasi kebidanan $(3,6 \%)$, toksemia gravidarum $(5,8 \%)$, trauma kebidanan meliputi laserasi jalan lahir dan hematom $(5,0 \%)$ dan laserasi perineum $(1,7 \%)$ serta trauma lainnya $(3,9 \%)$. Sedangkan angka morbiditas lainnya meliputi macam-macam infeksi dan penyakit yang menyertai kehamilan, persalinan dan nifas (Friedman, 2012).

Robekan jalan lahir selalu memberikan perdarahan dalam jumlah yang bervariasi banyaknya. Sumber perdarahan dapat berasal dari perineum, vagina, serviks, dan robekan uterus (Ruptura Uteri). Robekan jalan lahir banyak dijumpai pada pertolongan persalinan oleh dukun. Pertolongan persalinan oleh tenaga kesehatan dengan risiko rendah mempunyai komplikasi ringan sehingga dapat menurunkan Angka Kematian Ibu (AKI) maupun perinatal (Manuaba, 2013).

Angka kematian ibu di Indonesia tahun 2007 sebesar 228/100.000 kelahiran hidup, meningkat hingga $359 / 100.000$ kelahiran hidup pada tahun 2012 dan kembali turun kembali pada tahun 2015 mencapai 305/100.000 kelahiran hidup (Kemenkes RI, 2017).

Angka Kematian Ibu (AKI) di Provinsi Lampung tahun 2015 sebanyak 149 ibu meninggal saat proses kehamilan dan persalinan, di Kabupaten Lampung Utara sebanyak 21 ibu dari 10.979 jumlah kelahiran, di Kota Bandar Lampung sebanyak 20 ibu dari 20.200 jumlah kelahiran, di Lampung Selatan sebanyak 19 ibu dari 20.649 (Dinkes Provinsi Lampung, 2016). Pada tahun 2016 sebanyak $146 \mathrm{ibu}$ meninggal, dengan rincian AKI Kota Bandar Lampung sebanyak 19 orang dari 17.599 kelahiran, Kabupaten Lampung Selatan 
sebanyak 15 ibu dari 20.131 kelahiran dan Kabupaten Lampung Utara sebanyak $10 \mathrm{ibu}$ dari 11.120 Kelahiran. Penyebab kasus kematian ibu di Provinsi lampung tahun 2016 disebabkan oleh perdarahan sebanyak 45 kasus, hipertensi sebanyak 41 kasus, infeksi sebanyak 1 kasus, ganguan sistem peredaran darah sebanyak 8 kasus, kasus dan lain-lain sebanyak 45 kasus (Profil Provinsi Lampung, 2017).

Risiko tinggi/komplikasi adalah keadaan penyimpangan dari normal, yang secara langsung menyebabkan kesakitan dan kematian ibu maupun bayi. Berdasarkan distribusi di Kabupaten/kota maka cakupan tertinggi ada di Kabupaten Pringsewu (134.68\%) Terendah ada di Kabupaten Pesawaran $(45.01 \%)$ sedangkan Lampung Utara sebesar $72.51 \%$.

Beberapa faktor yang mempengaruhi terjadinya laserasi perineum yaitu faktor maternal, faktor janin, dan faktor penolong. Faktor maternal meliputi perineum yang rapuh dan oedema, primigravida, kesempitan pintu bawah panggul, kelenturan jalan lahir, mengejan terlalu kuat, partus presipitatus, persalinan dengan tindakan seperti ekstraksi vakum, ekstraksi forsep, versi ekstraksi dan embriotomi, varikosa pada pelvis maupun jaringan parut pada perineum dan vagina. Faktor janin meliputi janin besar, posisi abnormal seperti oksipitoposterior, presentasi muka, presentasi dahi, presentasi bokong, distosia bahu dan anomali kongenital seperti hidrosefalus. Faktor penolong meliputi cara memimpin mengejan, cara berkomunikasi dengan ibu, ketrampilan menahan perineum pada saat ekspulsi kepala, episiotomi dan posisi meneran (Mochtar, 2012).

Bahaya dan komplikasi ruptur perineum antara lain perdarahan, infeksi dan disparenia (nyeri selama berhubungan seksual). Perdarahan pada ruptur perineum dapat menjadi hebat khususnya pada robekan derajat dua dan tiga atau jika ruptur perineum meluas ke samping atau naik ke vulva mengenai klitoris. Laserasi perineum dapat dengan mudah terkontaminasi feses karena dekat dengan anus. Infeksi terjadi jika luka tidak dapat segera menyatu sehingga timbul jaringan parut. Jaringan parut yang terbentuk sesudah laserasi perineum dapat menyebabkan nyeri selama berhubungan (Winkjosastro, 2007)).

Perineum yang kaku dapat membuat robekan luas tak terhindarkan. Sekitar $70 \%$ ibu melahirkan pervagina mengalami trauma perineum (Winkjosastro, 2007). Berbagai cara untuk mengurangi robekan pada perineum dapat dilakukan, antara lain dengan senam kegel (kegel exercise) dan pijatan perineum pada ibu hamil trimester tiga. Pada saat kehamilan, tulang panggul ibu akan melebar demi mempersiapkan proses kelahiran nanti. Latihan kegel dan masase perineum selama hamil akan menjaga kekuatan panggul sekaligus menjaga kelenturan otot-otot perineum. Massage perineum dan senam kegel adalah cara yang paling efektif untuk menghindari terjadinya robekan pada perineum. Manfaat lain pada kehamilan adalah juga efektif untuk membantu otot dasar panggul lebih kencang dan elastis.

Ada beberapa cara yang dapat digunakan untuk mencegah terjadinya robekan perineum karena persalinan normal, diantaranya adalah mengajarkan ibu untuk sering melakukan senam Kegel, serta menganjurkan ibu untuk memilih posisi yang nyaman, meneran saat ada his, tidak mengangkat bokong saat meneran, bagi petugas kesehatan tidak melakukan dorongan pada fundus untuk membantu kelahiran bayi, serta melindungi perineum saat kepala mulai tampak 5-6 cm di depan vulva dengan satu tangan untuk menahan belakang kepala bayi agar tetap fleksi pada saat keluar.

Senam kegel adalah senam untuk menguatkan otot dasar panggul menjelang persalinan, tujuannya untuk menguatkan otot-otot dasar panggul, membantu mencegah masalah inkontinensia urine, serta dapat melenturkan jaringan perineum sebagai jalan lahir bayi. Sehingga seluruh ibu harus dimotivasi untuk menggerakan otot dasar panggul sedikit-sedikit dan sesering mungkin, perlahan dan cepat pada masa mendekati persalinan. Prosedur senam Kegel dapat diingat dan dilakukan bersama aktifitas yang berkaitan dengan kegiatan ibu sehari hari. Seperti saat ibu duduk di kamar mandi setelah berkemih dan ini adalah posisi relaks untuk mengkontraksi otot tersebut, serta pada 
saat ibu ingin tidur dan dalam keadaan apapun. Melakukan senam Kegel secara teratur dapat membantu melenturkan jaringan perineum ibu menyambut persalinan (Proverawati, 2012).

Penelitian Ridlayanti (2011) hubungan antara senam kegel dengan penyembuhan luka jahitan perineum pada ibu postpartum normal di RB Alfiatun Hasanah Kota Bandung. Ada perbedaan penyembuhan luka perineum sebelum dan sesudah senam kagel diperoleh nilai p-value 0,001 dimana $0,001<0,05$.

Pra survey telah dilakukan peneliti pada pasien yang mengalami Episiotomi mengatakan tidak diajarkan oleh petugas kesehatan di ruangan tentang senam kegel yang bermanfat untuk mempercepat penyembuhan luka. Senam kegel memang belum familiar digunakan untuk wanita hamil, dan lebih sering digunakan pada pasca persalinan, namun melihat data diatas dan besarnya manfaat senam kegel pada ibu hamil, maka peneliti tertarik untuk melakukan penelitian tentang pengaruh senam kegel terhadap penyembuhan luka ruptur.

\section{METODE}

Jenis penelitian yang digunakan dalam penelitian ini adalah penelitian kuantitatif dengan desain Quasi Eksperimental rancangan nonequivalent control group Design Populasi penelitian ini adalah seluruh ibu bersalin primi di Wilayah Kerja Puskesmas Kotabumi Udik Kabupaten Lampung Utara dengan jumlah sampel sebanyak 60 responden. Pada penelitian ini teknik pengumpulan data yaitu dengan menggunakan lembar observasi yaitu dilakukan dengan pengukuran penyembuhan luka responden. Setelah lembar observasi diisi, dilakukan pengolahan data dengan sistem komputer melalui tahap-tahap Editing, Processing, Cleaning dan Tabulating. Analisa data pada penelitian ini dengan analisa univariat adalah analisis satu variabel dapat disajikan dalam bentuk distribusi frekuensi dan analisa bivariat uji $t$ ( $t$-test independen).
HASIL

\section{Analisis Univariat}

Tabel 1: Distribusi Penyembuhan Luka pada Ibu yang Melakukan Senam Kegel dan Tidak Melakukan Senam Kegel

\begin{tabular}{llcccc}
\hline Kelompok & Kategori & \multicolumn{4}{c}{ Mean } \\
\hline \multirow{2}{*}{ Senam kegel } & Max & St. Dev. \\
\cline { 2 - 6 } & Sebelum & 10.67 & 9 & 3 & 1.124 \\
\hline \multirow{2}{*}{$\begin{array}{l}\text { Tidak senam } \\
\text { kegel }\end{array}$} & Sesudah & 4.27 & 13 & 6 & 0.828 \\
\cline { 2 - 6 } & Sebelum & 10.53 & 9 & 4 & 1.125 \\
\hline
\end{tabular}

Berdasarkan tabel di atas diketahui bahwa rata rata skor REEDA pada hari pertama pengukuran pada kelompok kegel sebesar 10.67 point dan pada hari ke 14 skala REEDA, rata-rata sebesar 4.27 point. Berdasarkan tabel diketahui bahwa rata rata skor REEDA pada hari pertama pengukuran pada kelompok tidak senam kegel sebesar 10.53 point dan pada pengukuran hari ke 14 rata -rata sebesar 5.27.

\section{Analisis Bivariat}

Tabel 2: Distribusi Perbedaan Penyembuhan Lukas pada Kelompok Kegel dan Kelompok Tidak Kegel

\begin{tabular}{lccccc}
\hline Penyembuhan Luka & Mean & $\begin{array}{c}\text { Beda } \\
\text { Mean }\end{array}$ & t-test & $\begin{array}{c}\mathrm{p} \\
\text { value }\end{array}$ & $\mathrm{n}$ \\
\hline Senam kegel & 6.400 & 1.133 & 2,255 & 0,028 & 30 \\
\hline Tidak senam kegel & 5.267 & & & & \\
\hline
\end{tabular}

Berdasarkan tabel di atas diketahui hasil uji statistik didapatkan p-value 0,028 (p-value $<\alpha=0,05$ ) berarti ada pengaruh senam kegel terhadap penyembuhan luka pada ibu post partum, terdapat selisih penyembuhan luka pada ibu post partum dimana ibu yang melakukan senam kegel lebih cepat sembuh jika dibandingkan dengan ibu yang tidak melakukan senam kegel dengan selish 1.133 point. Artinya dapat disimpulkan bahwa senam kegel dapaat mempercepat penyembuhan luka perineum. 


\section{PEMBAHASAN}

Luka dapat diartikan sebagai gangguan atau kerusakan integritas dan fungsi jaringan pada tubuh. Luka adalah rusaknya kesatuan atau komponen jaringan, dimana secara spesifik terdapat substansi jaringan yang rusak atau hilang. Luka adalah kerusakan kontinuitas kulit, mukosa membran dan tulang atau organ tubuh lain (Maryunani, 2014).

Penelitian Antini (2016) efektivitas senam kegel terhadap waktu penyembuhan luka perineum pada ibu post partum normal. Rata-rata lama waktu penyembuhan luka perineum pada kelompok senam kegel adalah 6 hari dengan batasan minimal 5 hari dan maksimal 7 hari. Hasil penelitian Ridlayanti (2013) didapatkan bahwa rata-rata hari penyembuhan luka perineum dengan menggunakan latihan kegel lebih yaitu 5-7 hari. Sedangkan menurut penelitian Dewi Dina (2013) yang meneliti tentang efektivitas mobilisasi dini terhadap kecepatan penyembuhan luka perineum didapatkan bahwa dari 16 responden sebagian besar responden (10) percepatan penyumbuhan luka lebih lambat $(>7)$ dan hanya 6 responden yang masuk kategori kesembuhan lukanya cepat.

Menurut pendapat peneliti, banyak faktor yang mempengaruhi penyembuhan luka, setiap responden memiliki faktor sendiri sehingga proses penyembuhan luka berbeda setiap responden. Pada kelompok senam kegel, berdasarkan hasil penelitian diketahui bahwa latihan kegel akan dapat memberikan pengaruh yang baik terhadap penyembuhan luka perineum dengan dilakukannya arahan pelaksanaan senam kegel dapat meningkatkan kemampuan fisik manusia apalagi jika dilaksanakan dengan tepat dan terarah, karena dengan latihan kegel dapat memperkuat otot-otot dasar panggul terutama otot pubococcygeal sehingga wanita dapat memperkuat otot-otot saluran kemih dan otot-otot vagina sehingga berefek terhadap percepatan proses penyembuhan luka perineum. selain kegel banyak gerakan yang dapat dilakukan oleh ibu post partum diantaranya adalah mengangkat panggul secara bertahap dan lain-lain

Luka adalah rusaknya struktur dan fungsi anatomis kulit normal akibat proses patologis yang berasal dari internal dan eksternal, serta mengenai organ tertentu (Potter \& Perry dalam Maryunani, 2014). Faktor-faktor yang mempengaruhi penyembuhan luka adalah faktor lokal, seperti oksigenasi, hematoma dan lain-lain. Faktor umum, terdiri dari usia, nutrisi, sepsis, steroid dan obat-obatan (Subiston dalam Maryunani, 2014). Faktor lainnya adalah gaya hidup dan mobilisasi (Kozier dalam Maryunani, 2014).

Penelitian Antini (2016) efektivitas senam kegel terhadap waktu penyembuhan luka perineum pada ibu post partum normal. Rata-rata lama waktu penyembuhan luka perineum pada kelompok mobilisasi dengan rata-rata jumlah hari adalah 7 hari, dengan batasan minimal 4 hari dan maksimal 9 hari.

Menurut pendapat peneliti responden yang tidak melakukan senam kegel, hanya sebagian kecil saja yang penyembuhannya cepat yaitu dari 15 orang sebanyak 3 (20\%) orang, berdasarkan hasil yang diperoleh dari penelitian maka diasumsikan bahwa senam kegel dapat mempercepat penyembuhan luka. Perilaku senam kegel tidak dilakukan dikarenakan banyak ibu yang tidak mengetahui manfaat senam kegel, hal ini menuru peneliti dapat disebabkan karena pendidikan responden rata-rata lulusan SMP yang sumber informasi terkait manfaat senam kegel sangat terbatas, selain itu banyak responden dengan IMT lebih dari normal yang menurut teori dapat mempengaruhi proses penymbuhan luka perineum. Petugas kesehatan dapat memberikan informasi halhal terkait penyembuhan luka sehingga responden dapat menghindari hal-hal yang dapat menyebabkan terganggunya proses penyembuhan luka. Menurut pendapat peneliti, hasil penelitian menunjukkan masih terdapat responden yang belum melaksanakan mobilisasi dini. Hal ini dimungkinkan dengan alasan klien merasa takut atau merasakan nyeri ketika melaksanakan mobilisasi dini, mobilisasi yang efektif dilakukan untuk ibu nifas dalam mempercepat proses penyembuhan luka 
perineum dengan senam kegel, diantaranya untuk memperbaiki sirkulasi darah, memperbarui sikap tubuh, memperbaiki otot pelvis/ dasar panggul seorang perempuan sehingga dibutuhkan peran petugas kesehatan untuk menyebarkan informasi yang baik dan benar sehingga menimbulkan efek positif dalam meningkatkan kesehatan klien dengan luka episiotomi.

Hasil penelitian ini menjelaskan bahwa ada pengaruh senam kegel terhadap penyembuhan luka pada ibu post partum. Hal ini sejalan dengan teori yang mengungkapkan bahwa senam kegel bermanfaat untuk mempercepat penyembuhan luka di perineum (Proverawati, 2012).

Gerakan - gerakan otot (otot pubococcygeal) pada senam kegel, berupa gerakan pengerutan dan peregangan (Ward, 2009). Efek dari gerakan otot tersebut antara lain melancarkan sirkulasi darah dan oksigen ke dalam otot dan jaringan di sekitar, seperti perineum. Manfaat dari oksigen yang lancar tersebut maka luka yang terdapat diperineum akan cepat sembuh karena efek dari oksigenisasi (meningkatkan ketersediaan oksigen dan nutrisi untuk penyembuhan luka) (Maryunani, 2015).

Hasil ini juga sejalan dengan penelitian yang dilakukan oleh Oya dan Sevgul (2015), hasilnya mengungkapkan bahwa efek dari latihan Kegel terjadi dalam 2 minggu setelah intervensi untuk membantu dalam meningkatkan sirkulasi di daerah perinum, membantu perineum sembuh dari episiotomi atau robek dan mengurangi kesempatan mengembangkan wasir. Juga, studi yang disepakati dengan (Fleten dan Nystad, 2012), yang melaporkan bahwa sejak dasar panggul latihan otot dilakukan dari hari setelah melahirkan sampai dua minggu kemudian akan meningkatkan nada dan elastisitas perineum, meningkatkan sirkulasi di daerah ini sehingga penyembuhan luka episiotomi akan lebih cepat. Sejalan dengan penelitian Antini (2016) efektivitas senam kegel terhadap waktu penyembuhan luka perineum pada ibu post partum normal. Rata-rata lama waktu penyembuhan luka perineum pada kelompok senam kegel adalah 6 hari dengan batasan minimal 5 hari dan maksimal 7 hari lebih cepat dibandingkan pada kelompok mobilisasi dengan rata-rata jumlah hari adalah 7 hari, dengan batasan minimal 4 hari dan maksimal 9 hari.

Menurut pendapat peneliti, dari hasil penelitian diketahui bahwa manfaat senam kegel yang dilakukan oleh ibu memiliki banyak manfaat khususnya pada penyembuhan luka perineum yang disebabkan oleh tindakan episiotomy yang dilakukan di daerah perineum. Pada masa penyembuhan luka yang lebih cepat, dengan penyembuhan luka yang lebih cepat dapat mengurangi kemungkinan adanya infeksi yang dapat terjadi karena adanya luka pada tubuh ibu.

Dari manfaat-manfaat ini dapat disimpulkan bahawa senam kegel sebaiknya menjadi tindakan yang rutin dilakukan oleh ibu pasca persalinan. Sehingga peran bidan sangat dibutuhkan dalam meningkatkan kegiatan ini. Bidan dapat mengajarkan senam kegel disaat ibu melakukan pemeriksaan kehamilan, sehingga ibu memahami bahwa senam kegel yang nanti akan dilakukan saat masa nifas sangat bermanfaat bagi dirinya khusunya pada pengurangan nyeri dan penyembuhan luka.

\section{KESIMPULAN}

Hasil penelitian menyimpulkan bahwa ada perbedaan penyembuhan luka pada ibu post partum yang melakukan senam kegel dan yang tidak melakukan senam kegel. Dimana pada ibu yang melakukan senam kegel proses penyembuhannya lebih baik. Artinya bahwa senam kegel dapat mempercepat penyembuhan luka perineum pada ibu post partum.

Berdasarkan kesimpulan tersebut, maka disarankan agar puskesmas melalui petugas kesehatan perawat dan bidan agar dapat memberikan informasi dan palatihan senam kegel bagi setiap ibu hamil dan ibu nifas di wilayah kerjanya. 


\section{DAFTAR PUSTAKA}

Antini, A; Trisnawati, I. \& Darwanty, J. (2016). Efektivitas Senam Kegel Terhadap Waktu Penyembuhan Luka Perineum Pada Ibu Post Partum Normal. Suara Forikes. 7(4): 212-216.

Dewi, Vivian N.L., \& Sunarsih, Tri. 2013. Asuhan Kebidanan pada Ibu Nifas. Jakarta: Salemba Medika

Dinas Kesehatan Provinsi Lampung. (2016). Profil Kesehatan Provinsi Lampung 2014. Lampung

Flaten and Nystad. (2012). Effect Of Antenatal Pelvic Floor Muscle Training On Labor And Birth.

Friedman. (2014). Buku Ajar Keperawatan Keluarga. Jakarta: EGC.

Kemenkes RI. (2013). Riset Kesehatan Dasar 2013. Jakarta

Manuaba. (2013). Ilmu Kebidanan, penyakit Kandungan dan KB. EGC: Jakarta

Maryunani, A. (2014). Perawatan luka seksio caesarea (SC) dan luka kebidanan terkini. Jakarta : TIM
Mochtar. R. (2013). Sinopsis Obstetrii. EGC: Jakarta

Potter and Perry. (2011). Buku Ajar Fundamental Keperawatan : Konsep, Proses \&. Praktek. Edisi 4. Vol 1. Jakarta: EGC

Proverawati dan Anggriyana TW. (2010) senam kesehatan dlengkapi dengan contoh gambar. Jogyakarta: Nuha Medika

Ridlayanti. (2011). Hubungan Antara Senam Kegel Dengan Penyembuhan Luka Jahitan Perineum Pada Ibu Postpartum Normal Di RB Alfiatun Hasanah Kota Bandung

Ridlayanti. (2011). Hubungan Antara Senam Kegel Dengan Penyembuhan Luka Jahitan Perineum Pada Ibu Postpartum Normal Di Rb Afiatun Hasanah Kota Bandung. [Thesis]. Universitas Airlangga.

Wiknjosastro, H. (2016). Ilmu kandungan. Jakarta: Yayasan Bina Pustaka Sarwono Prawirohardjo 